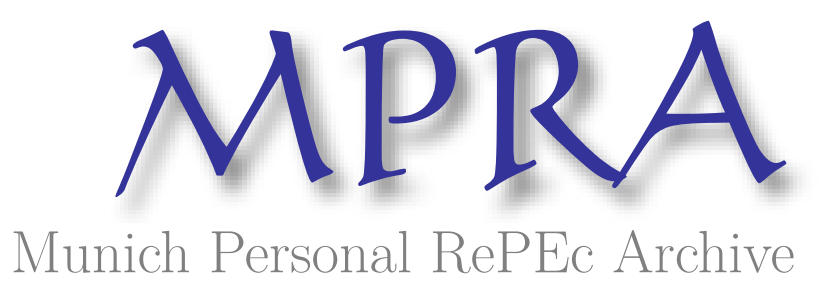

\title{
Public Policy Lessons from the Covid-19 Outbreak: How to Deal with it in the Post-Pandemic World?
}

Syed Abul, Basher and A.K. Enamul, Haque

25 November 2020

Online at https://mpra.ub.uni-muenchen.de/104337/

MPRA Paper No. 104337, posted 26 Nov 2020 11:29 UTC 


\title{
Public Policy Lessons from the Covid-19 Outbreak: How to Deal with it in the Post-Pandemic World?
}

\section{Syed Abul Basher ${ }^{2}$ and A.K. Enamul Haque ${ }^{3}$}

\begin{abstract}
Using cumulative confirmed cases of Covid-19 covering 163 countries, this paper tests several hypotheses that have received extensive attention in the popular media and academic research during the ongoing coronavirus pandemic. Our goal is to identify lessons for designing better public health policies in the post-pandemic era based on the past 6 months' experiences of these 163 countries. Based on 2SLS regression, we derive the following lessons. First, providing universal health care is a significant public health strategy for countries to help deal with similar outbreaks in the future. Second, tackling air pollution is a win-win solution, not only for better preparedness against Covid-19 or other airborne diseases, but also for the environment and climate change. Third, lockdowns may help to reduce community spread but its impact on reducing Covid-19 incidence is not statistically significant. Similarly, antimalarial drugs have no significant effect on reducing the spread of the disease. Fourth, countries should encourage home-based work as much as possible until some treatment or cure is found for the virus. Fifth, the lessons of past SARS experience helped contain the spread of the infection in East Asian countries; other countries must adjust their social and cultural life to the new normal: wearing masks, washing hands, and keeping a distance from others in public places.
\end{abstract}

\footnotetext{
${ }^{1}$ We would like to thank two anonymous reviewers and the discussants A.S.M. Alamgir, Fahmida Khatun, and Mohammad Mushtuq Husain and other participants at the East West University webinar for helpful comments and suggestions. We also thank Megan Foster for proofreading an earlier version of this paper. The usual disclaimer applies.

${ }^{2}$ Department of Economics, East West University, Dhaka, Bangladesh. syed.basher@ewubd.edu

${ }^{3}$ Department of Economics, East West University, Dhaka, Bangladesh. akehaque@ewubd.edu
} 


\section{Introduction}

What began as a seemingly isolated case of the phenomenon in Wuhan, China, in December 2019, led to a global coronavirus pandemic in early March 2020. The coronavirus outbreak is reminiscent of past global epidemics like SARS and MERS in 2002 and 2012, respectively. However, after 774 deaths around the world, SARS was brought under control or the virus simply vanished through the process of mutations. Although MERS has not been entirely eliminated yet, to date, it has killed 858 people and its spread remains localized in Saudi Arabia and South Korea (The Economist, 2020a). Finally, the recent outbreak, which is called SARS-Cov-2 or Covid-19, has been aptly dubbed by the Economist as "third time unlucky". As of the time of writing (23 July 2020), Covid-19 is now responsible for over 600,000 deaths and over 15 million confirmed cases of infection. ${ }^{4}$

Two of the most widely tracked outcomes of the coronavirus pandemic are the number of registered Covid-19 cases and the number of Covid-19 deaths. Another crucial parameter, the reproduction number, is not observed and is mathematically complex and computationally expensive to compute (Stojkoski et al., 2020). Besides the death toll, the effects of the widespread closure of factories, businesses, borders, and airports have led to rising unemployment and contraction of real economic activity. Barro et al. (2020) demonstrated that if a pandemic similar to the Great Influenza Pandemic of 1918-2020 occurred today, it would result in 150 million deaths worldwide with a decline in real per capita gross domestic product (GDP) of $6 \%$ for a typical country. The estimated pandemic-related economic losses are comparable to those observed in the Global Financial Crisis of 2008-2009.

Since the outbreak, countries across all continents have registered a significant rise in patients affected by Covid-19, but the extent of infection is not the same. After the coronavirus infections peaked in rich countries in the first 2-3 months of the pandemic, the Covid-19 infections are rising fast in poor countries (with India being heavily affected); while a few countries such as Australia, Japan, and Hong Kong are seeing a second Covid-19 wave. Although health services across the world are working hard to prevent deaths, the number of patients is rising exponentially. And even if a vaccine is found, the widespread vaccination will take several years to control the virus. The policymakers, on the other hand, are puzzled about what to do or how to amend their policies to prepare for the future.

In this study, our primary goal is to test several hypotheses concerning factors that have received wide attention both in the popular media and academic research in terms of their association with (or causation of) the coronavirus pandemic. What explains the rapid increase of Covid-19 patients across the world? Besides the popular prescription to halt the spread by keeping a distance from others and wearing masks

\footnotetext{
${ }^{4}$ https://coronavirus.jhu.edu/map.html, accessed 6 August 2020.
} 
in public places, are there any other strategies for governments to apply? Although it is evident that an increase in the number of Covid-19 patients is critically dependent on the number of tests completed in a country, are there any other factors that could explain the differences in Covid-19 patient numbers in different countries? The main novelty of our approach is to link the evidence from empirical analysis to designing public policy responses to pandemics. In so doing, we rely on the two stage least squares (2SLS) method, a popular empirical approach that is widely used to estimate causal relationships. However, we are careful not to claim a causal interpretation of our results, rather the findings confirm the relationship between outcome and treatment variables based on linear regression models.

The dependent variable of our empirical analysis is the number of confirmed cases of Covid-19. We used regression models and explained the outcome variable by a set of socio-economic variables encompassing economic, health, and environmental covariates. This estimation is challenging because the dependent variable is a response to the number of tests done to detect the presence or absence of coronavirus on a person. However, the number of tests performed in a country is also endogenous, which itself is dependent on the economic strength of the country. A richer country has the ability to deliver more tests for the detection of Covid-19 patients, whereas a poor country is likely to do fewer tests and hence may report a lower number of patients. As such, GDP or per capita GDP of a country also explains the number of tests performed in a country, which, inter alia, may explain the number of Covid-19 patients in a country. We therefore believe that a simple regression model is unlikely to provide efficient estimates of the parameters.

Coronavirus is an infectious disease and there are hypotheses that it spreads through the air. Consequently, people are advised to wear masks, keep their distance from others, and practice basic hygiene standards in public places to prevent the spread of the disease. As such, the role of air pollution in spreading the coronavirus pandemic in an area has received renewed attention. In general, even before the coronavirus pandemic, exposure to air pollution had been linked to rise of acute respiratory illness and related deaths. Air pollution-related health hazards are responsible for an estimated 8.8 million deaths annually and a loss of life expectancy of 2.9 years (Lelieveld et al., 2020). Recently, researchers established that the virus spreads through droplets, so covering faces with masks and keeping a distance from others were prescribed by WHO to combat its spread. However, WHO has recently reversed its guidance to say that transmission through the air cannot be ruled out, suggesting that the virus can persist in aerosol form. This study therefore tests the hypothesis whether the level of air pollution in a country is linked to the spread of the disease or not.

Clinical studies have also suggested that the spread of disease is linked to the distance that we maintain from an infected person, so keeping a distance from each other has also been suggested as an essential parameter to stop the spread (Bahl et al., 2020). At a macro level, therefore, we tested whether 
the density of a population, which is a proxy of the crowd-level in a location, is related to the spread of the disease or not.

Countries previously exposed to SARS were much better prepared in terms of use of masks and keeping a distance from each other to prevent the spread, so when Covid-19 hit these countries, a relevant hypothesis to test is to know whether past exposure to SARS had any impact on the spread of Covid-19.

There were claims that countries where people had taken antimalarial drugs like hydroxychloroquine or similar might have slowed down the spread of Covid-19. Following President Trump's support for the drug, there has been much hype surrounding hydroxychloroquine, even though scientific evidence regarding its effectiveness is scant (Pastick et al., 2020). Hence, in this cross-country study, we tested whether countries that had cases of malaria and that took preventive medicine had a lower rate of infection or not.

With the Covid-19 pandemic, many countries have experienced a complete collapse of their health services. However, some countries have done better than others. The pertinent question is to know whether the number of health care personnel or the overall health service delivery system had an impact on the spread. We therefore used cross-country data to test whether the number of doctors per 1000 population or the provision of universal health care in a country had an impact on reducing the spread of the disease.

Finally, one of the known strategies to prevent the community spread of Covid-19 is to impose local restrictions on people's mobility (i.e., lockdown). Though many countries have imposed strict mobility restrictions, some countries were reluctant to impose it; a few never imposed it strictly. We have used Google's mobility data by country (https://www.google.com/covid19/mobility/, accessed 8 June 2020) to find out the changes in mobility, which are measured as change in the level of mobility from when coronavirus was first detected in the country. Changes in the movement of a population are recorded through several variables. These variables are not always accurate but they show whether or not the population was staying at home or not. We therefore tested whether staying at home has been able to reduce the spread of the disease.

\subsection{Related literature}

Since the outbreak of the novel coronavirus in late December 2019, there has been an explosion ${ }^{5}$ of academic research into the cross-country variations in the diffusion of the coronavirus pandemic, among many other topics. An earlier paper by Adda (2016) on the economic determinants of virus spread found

\footnotetext{
${ }^{5}$ Between March 23, 2020 and July 20, 2000, researchers with an affiliation to NBER alone published 194 Covid-19 related papers. The list is being continuously updated (https://nber.org/wp_covid19_rco_07202020.html, accessed 6 August 2020.
} 
that limiting travel or closing down schools tended to benefit mostly younger people in the short term. In the longer run, transportation networks and economic cycles play a vital role in disseminating diseases within and across regions. ${ }^{6}$ Stojkoski et al. (2020) found that population size had a negative effect on the number of registered Covid-19 cases, implying that, in general, countries with smaller populations tended to act relatively slowly in the pandemic. Moreover, government health expenditure has a positive effect on Covid-19 cases, indicating that higher health spending is associated with greater testing capability and therefore increasing evidence for the coronavirus situation in a country. Jinjarak et al. (2020) demonstrated that the effectiveness of stringency measures was more potent in countries with a higher share of elderly people (65 or older) and with cooler temperatures over the January-April period. An interesting finding, which has implications for our study, is that higher population density, as found in Asia, is associated with a flatter mortality curve. Asia's experience of battling SARS has instilled a sense of preparedness in responding to a situation like the coronavirus crisis. The findings of Knittel and Ozaltun (2020) emphasized a greater need for keeping a distance from others ${ }^{7}$ in public places as well as a greater need for distancing at work. Qui et al. (2020) found that cities with a higher number of doctors had lower transmission rates, whereas cities with higher GDP per capita exhibited higher transmission rates. Their results also showed that cities with higher population density, adverse weather conditions, lower temperatures, or less rain experienced lower transmission rates. Finally, Yilmazkuday (2020) showed that being at home more and using less transit were correlated with fewer Covid-19 cases and deaths.

In this paper, we contribute to this growing literature by drawing some lessons from the cross-country variation in the social and economic determinants of the number of confirmed Covid-19 cases. Despite the unprecedented fiscal and monetary responses and the sweeping lockdowns to control coronavirus, the governments are currently grappling with the challenges in the post-pandemic world. We focus on broad public policy approaches that would help countries to prepare for future infectious diseases, which are becoming more common. Had we learned from the recent Ebola crisis (and not to mention the SARS outbreak in 2002), we would not be so ill-prepared for a global pandemic. It's no coincidence that two of our findings and conclusions intersect with Joe Biden's two boldest proposals ${ }^{8}$ — to establish universal health care and a serious national climate-change policy - to protect Americans from the dual shocks of public health and climate change.

\footnotetext{
${ }^{6}$ Adda (2016) noted that developed countries are not necessarily less prone to virus outbreaks because of increasing commercial ties with Africa and Asia, two continents that have closer contacts between humans and wild habitats.

${ }^{7}$ We prefer to use 'keeping a distance' instead of 'social distancing' in academic literature because 'social distancing' gives the impression of segregation within a society.

${ }^{8}$ The Economist (2020b).
} 
The rest of this paper is organized as follows. Section 2 discusses the model specifications, the choice of variables used in the empirical analysis, and some summary statistics of the variables. Section 3 presents the empirical results. Section 4 concludes the paper.

\section{Model specification and data}

The outcome variable $\left(y_{i}\right)$ of our analysis, the number of confirmed cases of Covid-19 per 100,000, is modeled via a linear regression framework as:

$$
y_{i}=\beta_{0}+\beta_{1} T_{i}+\sum_{j=2}^{k} \beta_{j} \boldsymbol{X}_{j i}+\delta f_{i}+u_{i}
$$

where $T_{i}$ is number of tests performed, $\boldsymbol{X}_{i}$ is a $k$ dimensional vector of exogenous socio-economic variables, $f_{i}$ captures fixed regional effects, and $u_{i}$ is the error term. $\beta_{0}$ and $\beta_{j}$ are the regression intercept and the vector of slope parameters comprising the contribution of each explanatory variable respectively. Our dependent variable is the total number of confirmed cases per capita, which reflects how rapidly coronavirus has increased relative to other countries. Given the similarity in the testing process around the world, the dependent variable is measured consistently.

We first estimate the multiple regression model above by using the ordinary least squares (OLS) method, adjusting the standard errors for heteroskedasticity. OLS is a standard statistical tool used by economists for linear models. However, given the potential endogeneity or reverse causality between Covid-19 tests performed in a country and the number of confirmed cases, we tested for the presence of endogeneity using the Durbin-Wu-Hausman test for endogeneity discussed in Davidson and MacKinnon (1993). The result gives us a chi-square statistic of 5.14 with the p-value of 0.023 , suggesting that the null hypothesis that regressor is exogenous is rejected at the $5 \%$ level. In other words, there is contemporaneous endogeneity between tests performed and the number of confirmed cases, so that an instrumental variable (IV) regression is required. Consequently, Equation (1) is also estimated via the two-stage least squares (2SLS) regression, which is a special case of the IV method. In the 2SLS regression, the number of tests is estimated in the first stage with macro-economic variables that reflect the ability of the country to perform such tests, and the predicted value is used as an instrument in the second stage to establish the relationship. The 2SLS estimator has the desirable small-sample properties and are robust to the presence of multicollinearity and misspecification (Kennedy, 2008, p. 179). As a check of robustness, we also present results obtained using the generalized method of moments (GMM) estimator. 


\subsection{Choice of independent variables}

The dependent variable, Covid-19 cases per 100,000 population, is taken from a publicly available Covid19 database $^{9}$ available for 217 countries and territories. The independent variables can be categorized as follows:

- Socio-economic variables: age dependency ratio, survival rate to age 65 , GNI per capita, domestic private health expenditure per capita, domestic general government health expenditure per capita, changes in the mobility of population resulting from lockdown.

- Health: number of Covid-19 tests performed, universal health coverage, hospital beds per 1,000, people with basic handwashing facilities including soap and water, births attended by skilled health staff, physicians per 1,000 people, community health workers per 1,000 people, BCG immunization, SARS experience, incidence of malaria, BCG and other contagious diseases.

- Pollution and climate: Particulate matter $\leq 2.5 \mu \mathrm{m}$ in diameter $\left(\mathrm{PM}_{2.5}\right)$, air pollution, ecosystem, EPI rank.

Data on the socio-economic variables were collected by country from several sources, which are listed in the references. The choice of variables follows the recent literature on cross-country patterns of Covid-19 infection - see, among others, Stojkoski et al. (2020) and Yilmazkuday (2020). Our goal was to use a parsimonious empirical framework that is common across countries while accounting for the socioeconomic differences in health, income, and climate as determinants of Covid-19 cases outcomes. Several other variables were dropped because of a lack of coverage in the dataset across different countries. We ran a number of regressions to arrive at the final empirical specification on the basis of outcomes that yield the desired sign, strength of relationship, and goodness of fit of the model. We also consider stepwise regression and LASSO which tend to yield a more parsimonious set of covariates in a regression, but the results obtained are limited from the policymaker's perspectives. ${ }^{10}$ We use the variance inflation factor (VIF) to test for multicollinearity in the OLS regression (Model 3 in Table 2). The mean VIF is 2.61, with the highest VIF for universal health care is 6.13, suggesting that our preferred specification is free of multicollinearity.

\subsection{Descriptive statistics}

Table 1 presents some summary statistics of the variables. The average confirmed cases of Covid-19 per 100,000 people is 223 , whereas the average number of tests performed per 1,000 people is around 19. Both of these variables are highly volatile, as their standard deviation exceeds their mean values. The

\footnotetext{
${ }^{9} \mathrm{https}: / /$ ourworldindata.org/coronavirus-source-data, accessed 6 August 2020.

${ }^{10}$ These results are available upon request from the corresponding author.
} 
average age dependency ratio is approximately 59, indicating that around 59\% of the population in our sample is not of working age. The average universal health care (UHC) service coverage index is 64, implying that about $64 \%$ of the global population is covered by essential health services. This average value, of course, masks the wide variation across countries. For example, some countries in the lowincome group (e.g., Comoros and Zimbabwe) achieved a higher UHC score than several lower-middleincome countries like Bangladesh and Nigeria. As such, we have also reported the coefficient of variation in the descriptive statistics table. The average number of practicing doctors per 1,000 inhabitants is around 2, indicating that we have a shortage of doctors worldwide. The average $\mathrm{PM}_{2.5}$ level $\left(\mu \mathrm{g} / \mathrm{m}^{3}\right)$ in the air is over 29, which is considered to be moderate air quality, based on the 24-hour $\mathrm{PM}_{2.5}$ level. The inclusion of mobility statistics (i.e., the stay-at-home index) in the model significantly reduces the number of observations to around 108. Therefore, stay-at-home mobility was not considered in our preferred 2SLS/GMM model, but is included in the OLS model. The summary statistics of the remaining variables are self-explanatory and therefore are not discussed here for brevity.

\section{Empirical results}

Table 2 presents the main empirical results. We use a one-tailed test of significance on the coefficients because we are testing whether the covariates have the expected impact on Covid-19 cases as hypothesized in the literature. One of our leading independent variables, number of tests, has a positive and statistically significant effect on confirmed Covid-19 cases, as expected. However, as already discussed, because the number of tests responds endogenously and have a reverse causal relationship with the number of confirmed cases, we used the 2SLS estimation technique and instrumented it with the predicted value from the first-stage equation. To this end, we consider three instruments to correct for endogeneity. Our first instrument is GNP per capita which reflect a country's financial ability to conduct Covid-19 tests (an ability measure); the second instrument is the public expenditure on health care which captures a country's capacity to test the coronavirus (a capability measure); and the third instrument, which we consider a measure of public health status, is the survival to age 65 that indicates the progress ${ }^{11}$ made against chronic fatal diseases such as cardiovascular diseases (Olshansky, 2015). The idea is to exploit the exogenous variation in the three instruments to obtain a consistent estimation of the predicted value of the number of tests in the first stage regression.

We conducted several diagnostic tests concerning the overall fit of the 2SLS/GMM models. The $p$ value of the first-stage F-statistic is zero, indicating that the instruments are not weak. Both 2SLS and GMM models are overidentified because we have utilized three instruments for a single included

\footnotetext{
${ }^{11}$ Needless to say, the primary reason behind the global rise in longevity is because of declining infant mortality.
} 
endogenous regressor (i.e., number of Covid-19 tests performed per 1000). The Hansen J-statistic for overidentifying restrictions test indicates that the null hypothesis that the instruments are exogenous cannot be rejected at the 5\% level of significance. Hence, our choice of the instruments pass the tests of both instrument relevance and instrument exogeneity.

In Table 2, we observe that the 2SLS point-estimated coefficient of Covid-19 tests is more than twofold higher than the OLS coefficient, implying that the OLS coefficients are biased downward because of reverse causality. The 2SLS estimates are immune to downward bias because, as we have instrumented it with GDP per capita and other related variables, the number of tests is now an exogenous variable.

Both the 2SLS, GMM and OLS estimates suggest the negative and statistically significant effect of the age dependency ratio on Covid-19 cases, suggesting that countries with a relatively higher dependency ratio would record a lower Covid-19 case than countries with a lower dependency ratio. One explanation for this apparently counter-intuitive result is that families with relatively high dependency tend to stay indoors and hence are less exposed to the virus. Thus because of the low probability of exposure to the virus compared with countries with a low dependency ratio where more people go outside for work, countries with higher dependency had a slower rate of infection. Exposure is linked to the amount of time people spend in public transport, workplaces, and restaurants. It is also likely that families with older people at home also took extra precautions to protect themselves when they went out and prevented carrying the virus into their homes. Thus countries with larger family sizes and a higher dependency ratio were comparatively less exposed and experienced less spread of the disease. This socio-cultural variable explains differences in the spread of the disease across countries.

UHC had a negative effect on the number of confirmed cases, thereby confirming our hypothesis that the availability of universal health coverage builds up a better health status in the population and hence it helps to contain the spread of coronavirus in a country. This is an important public policy variable for countries to monitor in the future. This variable may have been able to contain the spread for two reasons: (a) it reflects the better preparedness of the country to deal with a pandemic, and (b) it helped to maintain better health status among the population. The estimated value indicates that when the public health infrastructure is inadequate to deal with viral outbreaks, human (particularly health personnel) exposure to infection rises, as seen from the Ebola epidemic in Sierra Leone (Rasul, 2020). In countries like China, Sri Lanka, Viet Nam, Thailand, and Turkey, UHC has been a critical investment, as their relative success at weathering Covid-19 shows compared with other developing countries. Underfunded health systems have exposed the acute shortages of hospital beds, intensive care facilities, ventilators, and other equipment during this unprecedented time of need. In countries like Bangladesh, where out-of-pocket health 
expenditure is nearly $65 \%$ of total costs, private hospitals have shut their doors to the general public, wreaking havoc on human health.

The findings of several recent studies have suggested a positive correlation between high levels of air pollution (measured by, say, $\mathrm{PM}_{2.5}$ ) and coronavirus cases, including deaths. This is an interesting result, and it statistically confirms the hypothesis that better air quality is an important public policy tool for countries to deal with Covid-19-like situations. A nationwide survey by Wu et al. (2020) of more than 3,000 counties in the United States showed that a small increase $\left(1 \mu \mathrm{g} / \mathrm{m}^{3}\right)$ in $\mathrm{PM}_{2.5}$ was associated with an $8 \%$ increase in the Covid-19 death rate. Their result remained robust after various secondary and sensitivity analyses. Similarly, Cole et al. (2020) found that a $1 \mu \mathrm{g} / \mathrm{m}^{3}$ increase in $\mathrm{PM}_{2.5}$ concentration in the Netherlands was associated with 9.4 more Covid-19 cases, 3.0 more hospital admissions, and 2.3 more deaths. Their results also survived several robustness checks. Isphording and Pestel (2020) found that air pollution raised the number of confirmed cases of Covid-19. In particular, a one standard deviation rise in air pollution was associated with a $30 \%$ increase in deaths in males and a $35 \%$ increase in females 3 to 12 days after developing coronavirus symptoms. Because Covid-19 is a recent phenomenon, it is likely that the link between air pollution and coronavirus points to a correlation rather than causation, since other factors such as population density affect air pollution. However, a study by Cui et al. (2003) showed that in the 2003 SARS outbreak in China, patients from regions with high air pollution were twice as likely to die from SARS than those from areas with low air pollution.

The negative coefficient of SARS experience suggests that previous experience of SARS played a crucial role in limiting coronavirus infections and deaths. Helped by the SARS experience in 2002-2003, countries in East Asia like China, Singapore, South Korea, and Taiwan took three essential measures to stop the spread of the virus: (a) travel bans on people from areas with high infection rates, (b) imposition of quarantine rules to limit known or suspected carriers from spreading the virus to others, and (c) total shutdown and keeping one's distance to prevent community-level transmission (Graham-Harrison, 2020). The defining feature that separates the collectivist East Asian countries from that of Europe was aptly expressed by Fox (2020) in a Bloomberg column:

"So the Asian countries that had experienced SARS and MERS not only took pandemic scenarios seriously, but also seem to have had the right pandemic scenarios for this particular disease - ones that envisioned some possibility of halting rather than just slowing its spread. They could also count on much of the population remembering the previous outbreak, knowing what they were supposed to do and having stashes of surgical masks in their apartments." 
Our findings help to dispel concerns about the support for using malaria drugs such as hydroxychloroquine as a treatment for Covid-19. In early April 2020, President Donald Trump branded hydroxychloroquine as a "game-changer" and, addressing to journalists from the White House podium, he said: "What do you have to lose?" (Kuchler 2020a). India, a significant producer of hydroxychloroquine, recommended its health workers to take the drug and banned it from being exported (Kuchler, 2020a). The estimated coefficients on malaria indicate that, although the association between malaria and Covid-19 cases is negative, the relationship is not statistically significant. Pastick et al. (2020) reviewed a handful of clinical studies that examined the effectiveness of hydroxychloroquine as a potential method of prevention and treatment for Covid-19. They raised concerns about the validity of the findings of small clinical trials (the largest had only 100 patients) and therefore could not draw any definitive conclusions about the efficacy of hydroxychloroquine as a potential Covid-19 treatment. Not surprisingly, in June 2020, the Food and Drug Administration revoked approval for malaria drugs to treat Covid-19 patients (Kuchler, 2020b). ${ }^{12}$

The estimated coefficients on day and day squared suggest a U-shape relationship between cumulative Covid-19 cases and the number of days passed since the first detection. This indicates that as of July 2020, the general trend is that the infection is increasing at an increasing rate despite all the measures that the world has taken so far, albeit not a statistically significant effect. Moreover, as a whole, the world has not yet come to the point of flattening the curve of new Covid-19 infections, which is demonstrated by the positive coefficient of day squared. Indeed, as the time writing, although the rate of new Covid-19 cases in Europe is slowing, in other parts of the world (Africa, India, Latin America, and the United States), the pandemic is gaining momentum. In fact, some Asian countries are experiencing a second wave of coronavirus cases, dashing hopes for quick containment of the Covid-19 virus.

Our findings also cast doubt on what may seem like an obvious connection between a country's population density and its vulnerability to infections. The estimated coefficients of population density are small and statistically insignificant, suggesting no meaningful link between population density and confirmed cases of Covid-19 at the global level. However, this result does not rule out the possibility of a positive association between population density and virus infection at the individual country or, for that matter, at a city level, as reported by Arbel et al. (2020) for Israeli cities, among other studies.

Related to this, the coefficients on fixed regional effects also show that East Asia has done better than the rest of the world in managing the coronavirus outbreak. The model, therefore, used East Asia as the base and compared other regions with it. The estimates for Africa, the Caribbean, Latin America, and the Middle East are positive and statistically significant, suggesting a higher prevalence of confirmed cases of Covid-19 than that in East Asia. The positive coefficients for North America are directionally accurate,

\footnotetext{
${ }^{12}$ That said, some studies have found that using chloroquine (an antimalaria drug) is a potent inhibitor of SARS virus; see Vincent et al. (2005), among others.
} 
although it is statistically significant only in the GMM model. The negative coefficients for South Asia are puzzling, given the steep rise in confirmed Covid-19 cases in India, but they are statistically insignificant in all the three regressions.

For the last three variables in Table 1 (namely, real GNI per capita, domestic public health care expenditure and survival at 65), only the OLS coefficients are reported because these variables are also used as instruments for the number of tests performed in the 2SLS and GMM regressions. The coefficient of GNI per capita is positive but statistically insignificant. In March-April 2020, when the coronavirus pandemic was ravaging Italy, Spain, and other European countries, both media reports and public discourse concluded prematurely that Covid-19 was a rich countries' disease. A growing number of academic papers also found a positive association between GDP per capita and Covid-19 cases (e.g., Farzanegan et al., 2020). The typical explanation provided is that richer countries are more connected to international trade and travel, and therefore are more exposed to the coronavirus pandemic. Though this may have been right in the initial phase of the spread of the disease, it may not be true in the case of community infection. As such, we think that the 2SLS/GMM model provides a better explanation and that GNI per capita is not the correct explanatory variable for the spread of the disease; in other words, Covid-19 is not a curse on the rich nations. We think that because of higher income, rich countries were able to do more tests and thus they had more cases of infection.

The coefficient of domestic public health expenditure is consistent with the notion that public spending on health is central to keeping coronavirus under control. Still, the statistical significance of this relationship is not confirmed. Finally, the coefficient of survival at 65 indicates a positive association with people over the age of 65 and the Covid-19 virus; however, once again, this relationship is not statistically significant. However, we conclude that the correct model for explaining the spread of Covid19 infection is in the Models 1 or 2, and not in Model 3, which has many endogeneity problems. ${ }^{13}$

\section{Conclusions}

This study used Covid-19-related data for the 6 months up to 13 July 2020 from 217 countries. However, when we incorporated the socio-economic data, the number of observations was reduced to 163 and our empirical results are based on these. We began this research with several hypotheses in mind. We were

\footnotetext{
${ }^{13}$ We also tested the impact of lockdown (proxied by Google's mobility data on stay-at-home lockdown) on the number of Covid-19 cases. The OLS estimates in Table 2 shows that although staying-at-home is negatively associated with the number of confirmed cases of Covid-19, its impact on the disease outbreak is statistically insignificant. This suggests that a total lockdown is not necessary, as long as people take the necessary precautions such as wearing face masks, washing hands, and maintain distance in public places. The inclusion of this variable sharply reduces the number of observations (from 163 to 108) and given its statistical insignificance we have refrained from using it in the 2SLS and GMM models.
} 
looking for effective public policies that could help countries to prepare against any future coronavirus infections. We know that medical science researchers had pointed out that the use of masks and keeping a distance from others in public places reduces infections, and that lockdown policies would reduce the community spread of Covid-19 infections. We understand that these are the most critical strategies for containing the spread of Covid-19 infections once the disease is found in a country. However, we want to know whether there are any lessons in terms of better public health policy from our 6-month experience so that countries are better prepared to deal with future episodes.

Using the 2SLS model, we drew several conclusions from a public policy perspective. First, the number of tests in a country increased the number of confirmed Covid-19 cases in any country, but the provision of UHC would be a significant public health strategy for countries to help deal with Covid-19-like outbreaks in future. Countries must develop policies to ensure a credible universal health care system to prevent future outbreaks.

Second, air pollution is an important parameter for the spread of diseases. Therefore, countries must implement strategies to reduce air pollution in cities. This is probably a win-win solution for the environment, health, and climate change. Policies to reduce air pollution often entail a reduction in the use of fossil fuel in transport systems, which improves air quality, reduces acute respiratory infections, and also reduces carbon footprints.

Third, lockdowns may help to reduce community spread but their impact is not statistically proven. Similarly, antimalarial drugs did not have a significant effect on reducing the spread of the disease.

Fourth, working outside the home has an impact on the spread of the pandemic, as it increases exposures to the virus during an outbreak. Therefore, it is essential to note that in the future, until we have a cure for the virus, countries should maintain home-based work as much as possible.

Fifth, countries that have adjusted to the "new normal" of using masks and maintaining a distance from others in public places (a lesson learned by SARS-affected countries) have reduced the spread of the infection. As such, countries must adjust their social and cultural life to the new normal: wearing masks and keep a distance from others in public places. 
Table 1. Descriptive statistics

\begin{tabular}{|c|c|c|c|c|}
\hline Variable List & Average & Std Dev & $\begin{array}{l}\text { Coef. of } \\
\text { Var }\end{array}$ & $\begin{array}{l}\text { No of } \\
\text { Obs. }\end{array}$ \\
\hline No. of Covid-19 patients per 100K population* & 223.74 & 398.97 & 1.78 & 216.00 \\
\hline Percent of dependent population** & 58.75 & 16.58 & 0.28 & 194.00 \\
\hline $\begin{array}{l}\text { Percent of population covered under universal health care } \\
*_{*}\end{array}$ & 64.03 & 15.55 & 0.24 & 184.00 \\
\hline No. of doctors per 1,000 population & 1.91 & 1.65 & 0.87 & 165.00 \\
\hline Mean level of $\mathrm{PM}_{2.5}\left(\mu \mathrm{g} / \mathrm{m}^{3}\right)^{* *}$ & 29.29 & 19.34 & 0.66 & 241.00 \\
\hline $\begin{array}{l}\text { Stay at home index (indexed between } 0 \text { and } 100 \text {, where } 100 \\
=\text { maximum mobility restriction and } 0=\text { minimum or no } \\
\text { mobility restriction) })^{* * *}\end{array}$ & 0.42 & 0.22 & 0.52 & 135.00 \\
\hline Number of SARS cases (in 2003)** & 0.90 & 0.30 & 0.33 & 281.00 \\
\hline Incidence of malaria per 1,000 population at risk $* *$ & 32.07 & 88.67 & 2.76 & 281.00 \\
\hline No. of days since first detection* & 153.38 & 36.70 & 0.24 & 218.00 \\
\hline Square of (no. of days since first detection)* & 24866.11 & 11957.80 & 0.48 & 218.00 \\
\hline Density of population per $\mathbf{k m}^{2 * *}$ & 360.37 & 1573.68 & 4.37 & 200.00 \\
\hline GNI per capita (PPP adjusted)** & 14326.19 & 18885.73 & 1.32 & 194.00 \\
\hline Percent of public health expenditure in the budget $* *$ & 0.05 & 0.11 & 2.33 & 171.00 \\
\hline Survival rate beyond 65 years of age ( $\%$ of cohort) $* *$ & 80.62 & 11.75 & 0.15 & 195.00 \\
\hline No. of tests performed per $100 \mathrm{~K}$ population* & 18.77 & 50.06 & 2.67 & 281.00 \\
\hline
\end{tabular}

Note: * Data as of 13 July 2020. ** Latest available data. *** as of 8 June 2020. 
Table 2. Socio-economic determinants of confirmed cases of Covid-19

\begin{tabular}{|c|c|c|c|}
\hline Dependent variable: & Model 1 & Model 2 & Model 3 \\
\hline Cumulative No. of Covid-19 patients per $100 \mathrm{~K} *$ & 2SLS & GMM & OLS \\
\hline \multirow{2}{*}{ No. of Covid-19 tests performed per 1000} & $5.846 * *$ & $4.222 * *$ & $2.317 * *$ \\
\hline & $(2.04)$ & $(1.75)$ & $(1.97)$ \\
\hline \multirow[t]{2}{*}{ Percent of dependent population } & $-12.24 * * *$ & $-10.17 * * *$ & $-14.53 * * *$ \\
\hline & $(-3.13)$ & $(-2.96)$ & $(-2.49)$ \\
\hline \multirow[t]{2}{*}{ Universal health care coverage } & $-10.12 * *$ & $-7.320 * *$ & -11.90 \\
\hline & $(-2.03)$ & $(-1.69)$ & $(-1.27)$ \\
\hline \multirow[t]{2}{*}{$\mathrm{PM}_{2.5}$ level } & $4.718 * *$ & $3.383 *$ & $7.270 * *$ \\
\hline & $(1.90)$ & $(1.54)$ & $(1.72)$ \\
\hline \multirow{2}{*}{ Cases of SARS } & $-0.0294 *$ & $-0.0271 *$ & 5.872 \\
\hline & $(-1.40)$ & $(-1.30)$ & $(1.06)$ \\
\hline \multirow[t]{2}{*}{ Incidence of malaria per 1000} & -0.0746 & -0.00761 & -0.0790 \\
\hline & $(-0.40)$ & $(-0.04)$ & $(-0.17)$ \\
\hline \multirow[t]{2}{*}{ No. of days since first detection } & -4.987 & -4.268 & -07.017 \\
\hline & $(-0.70)$ & $(-0.62)$ & $(-0.57)$ \\
\hline \multirow[t]{2}{*}{ Square of (no. of days since first detection) } & 0.0188 & 0.0172 & 0.0266 \\
\hline & $(0.85)$ & $(0.80)$ & $(0.71)$ \\
\hline \multirow[t]{2}{*}{ Density of population per $\mathbf{k m}^{2}$} & -0.0250 & 0.0182 & -0.166 \\
\hline & $(-0.30)$ & $(0.25)$ & $(-0.94)$ \\
\hline \multirow[t]{2}{*}{ Africa } & $204.9 * * *$ & $222.7 * * *$ & $351.7 * * *$ \\
\hline & $(2.94)$ & $(3.27)$ & $(2.68)$ \\
\hline \multirow[t]{2}{*}{ Asia } & 81.06 & 130.4 & $232.6 *$ \\
\hline & $(0.68)$ & (1.18) & $(1.38)$ \\
\hline \multirow[t]{2}{*}{ Caribbean } & $157.5 * *$ & $153.5^{* *}$ & $302.9 * *$ \\
\hline & $(1.91)$ & $(1.88)$ & $(1.99)$ \\
\hline \multirow[t]{2}{*}{ East Asia (base) } & 0 & 0 & 0 \\
\hline & $()$. & $()$. & (.) \\
\hline \multirow[t]{2}{*}{ Europe } & -6.682 & 79.84 & 107.1 \\
\hline & $(-0.05)$ & $(0.64)$ & $(1.11)$ \\
\hline \multirow[t]{2}{*}{ Latin America } & $484.0 * * *$ & $476.5^{* * *}$ & $604.8 * * *$ \\
\hline & $(4.68)$ & $(4.62)$ & $(3.44)$ \\
\hline \multirow[t]{2}{*}{ Middle East } & $249.4 * *$ & $278.7 * *$ & $295.4 * *$ \\
\hline & $(1.86)$ & $(2.13)$ & $(1.76)$ \\
\hline \multirow[t]{2}{*}{ North America } & 295.8 & $382.4 *$ & -1385.3 \\
\hline & $(1.16)$ & $(1.59)$ & $(-0.99)$ \\
\hline \multirow[t]{2}{*}{ South Asia } & -152.9 & -78.63 & -269.8 \\
\hline & $(-1.17)$ & $(-0.69)$ & $(-0.81)$ \\
\hline
\end{tabular}




\begin{tabular}{|c|c|c|c|}
\hline $\begin{array}{l}\text { Dependent variable: } \\
\text { Cumulative No. of Covid-19 patients per 100K * }\end{array}$ & $\begin{array}{c}\text { Model } 1 \\
\text { 2SLS }\end{array}$ & $\begin{array}{c}\text { Model } 2 \\
\text { GMM }\end{array}$ & $\begin{array}{c}\text { Model } 3 \\
\text { OLS }\end{array}$ \\
\hline \multirow[t]{2}{*}{ Stay at home mobility index } & & & -95.42 \\
\hline & & & $(-0.55)$ \\
\hline \multirow[t]{2}{*}{ GNI per capita (PPP adjusted) } & & & 0.00771 \\
\hline & & & $(1.27)$ \\
\hline \multirow[t]{2}{*}{ Percent of public health expenditure in the budget } & & & -66.02 \\
\hline & & & $(-0.57)$ \\
\hline \multirow[t]{2}{*}{ Survival rate beyond 65 years of age ( $\%$ of cohort) } & & & 2.628 \\
\hline & & & $(0.41)$ \\
\hline \multirow[t]{2}{*}{ Constant } & $1456.6 * *$ & $1112.0^{*}$ & 1517.5 \\
\hline & $(1.70)$ & $(1.42)$ & $(1.13)$ \\
\hline Observations & 163 & 163 & 108 \\
\hline Adjusted $R^{2}$ & 0.30 & 0.43 & 0.50 \\
\hline
\end{tabular}

Note: $t$ statistics are given in parentheses (for a one-tailed test). ${ }^{*} p<.1{ }^{* * *} p<.05 ;{ }^{* * *} p<.01$ 


\section{References}

Adda, J. (2016). Economic activity and the spread of viral diseases: Evidence from high frequency data. Quarterly Journal of Economics 131, 891-941.

Arbel, Y., Fialkoff, C., Kerner, A. and Kerner, M. (2020). Do population density, socio-economic ranking and Gini index of cities influence infection rates from coronavirus? Israel as a case study. Mimeo, July 8 , 2020.

Bahl, P. et al., (2020) Airborne or droplet precautions for health workers treating coronavirus disease 2019? The Journal of Infectious Diseases, jiaa189. https://doi.org/10.1093/infdis/jiaa189

Barro, R.J., Ursúa, J.F. and Weng, J. (2020) The coronavirus and the Great Influenza Pandemic: Lessons from the "Spanish Flu" for the coronavirus's potential effects on mortality and economic activity. NBER Working Paper No. 26866, Cambridge, MA

Cole, M.A., Ozgen, C. and Strobl, E. (2020). Air pollution exposure and COVID-19. IZA Discussion Paper No. 13367. Available at SSRN: https://ssrn.com/abstract=3628242

Cui, Y., Zhang, Z.F., Froines, J., et al. (2003). Air pollution and case fatality of SARS in the People's Republic of China: An ecologic study. Environ Health 2, Article 15.

Davidson, R. and MacKinnon, J. (1993) Estimation and Inference in Econometrics, New York: Oxford University Press.

The Economist (2020a) The origin of Covid-19. 2 May 2020.

The Economist (2020b) Joe Biden's good pandemic. 23 May 2020.

Farzanegan, M.R., Feizi, M. and Gholipour, H.F. (2020) Globalization and outbreak of COVID-19: An empirical analysis. CESifo Working Paper No. 8315, Available at SSRN:

https://ssrn.com/abstract=3618839

Fox, J. (2020). What prepares a country for a pandemic? An epidemic helps. Bloomberg, 18 March 2020.

Graham-Harrison, E. (2020) Experience of SARS a key factor in countries' response to coronavirus. The Guardian, 15 March 2020.

Isphording, I.E. and Pestel, N. (2020). Pandemic meets pollution: Poor air quality increases deaths by Covid-19. IZA Discussion Paper No. 13418. Available at SSRN: https://ssrn.com/abstract=3643182

Jinjarak, Y. et al. (2020) Accounting for global COVID-19 diffusion patterns, January-April 2020. NBER Working Paper No. 27185, Cambridge, MA

Kennedy, P. (2008) A Guide to Econometrics, $6^{\text {th }}$ Edition, Blackwell Publishing, Malden, MA

Knittel, C.R. and Ozaltun, B. (2020) What does and does not correlate with COVID-19 death rates. NBER Working Paper No. 27391, Cambridge, MA 
Kuchler, H. (2020a). Trump's malaria drug hope: 'game changer' or dangerous gamble? Financial Times, 14 April 2020.

Kuchler, H. (2020b). FDA revokes approval for malaria drug used by Trump. Financial Times, 15 June 2020.

Lelieveld, J. et al. (2020). Loss of life expectancy from air pollution compared to other risk factors: A worldwide perspective, Cardiovascular Research, https://doi.org/10.1093/cvr/cvaa025

Olshansky S.J. (2015) Has the rate of human aging already been modified?. Cold Spring Harbor perspectives in medicine, 5(12), a025965. https://doi.org/10.1101/cshperspect.a025965

Pastick, K.A. et al. (2020). Review: Hydroxychloroquine and chloroquine for treatment of SARS-CoV-2 (COVID-19). Open Forum Infectious Diseases 7, ofaa130. https://doi.org/10.1093/ofid/ofaa130

Qiu, Y., Chen, X. and Shi, W. (2020). Impacts of social and economic factors on the transmission of coronavirus disease 2019 (COVID-19) in China. Journal of Population Economics 33, 1127-1172.

Rasul, I. (2020). The economics of viral outbreak. AEA Papers and Proceedings 110, 265-268.

Stojkoski, V. et al. (2020) The socio-economic determinants of the coronavirus disease (COVID-19) pandemic. medRxiv, doi: https://doi.org/10.1101/2020.04.15.20066068

Vincent, M.J. et al. (2005). (2005). Chloroquine is a potent inhibitor of SARS coronavirus infection and spread. Virology Journal 2, 69. https://doi.org/10.1186/1743-422X-2-69

$\mathrm{Wu}, \mathrm{X}$. et al. (2020). Exposure to air pollution and COVID-19 mortality in the United States. medRxiv 2020.04.05.20054502. https://doi.org/10.1101/2020.04.05.20054502

Yilmazkuday, H. (2020). Stay-at-home works to fight against COVID-19: International evidence from Google mobility data. Available at SSRN: https://ssrn.com/abstract=3571708 